BULLETIN Bulletin hispanique

HispaniQuE Université Michel de Montaigne Bordeaux

115-1 | 2013

Poésie et société en Espagne : 1650-1750

\title{
Una polémica literaria en la Sevilla de la segunda mitad del XVII
}

el Templo panegírico (1663) de Fernando de la Torre Farfán atacado y defendido

Juan Montero

\section{OpenEdition}

Journals

Edición electrónica

URL: http://journals.openedition.org/bulletinhispanique/2328

DOI: 10.4000/bulletinhispanique.2328

ISSN: 1775-3821

Editor

Presses universitaires de Bordeaux

Edición impresa

Fecha de publicación: 1 junio 2013

Paginación: 27-48

ISBN: 978-2-86781-898-1

ISSN: 0007-4640

Referencia electrónica

Juan Montero, «Una polémica literaria en la Sevilla de la segunda mitad del XVII », Bulletin hispanique

[En línea], 115-1 | 2013, Publicado el 01 junio 2016, consultado el 20 abril 2019. URL : http://

journals.openedition.org/bulletinhispanique/2328; DOI : 10.4000/bulletinhispanique.2328 


\title{
Una polémica literaria en la Sevilla de la segunda mitad del XVII: el Templo panegírico (1663) de Fernando de la Torre Farfán atacado y defendido*
}

\author{
Juan Montero \\ Universidad de Sevilla - España
}

Les polémiques entre écrivains sont un facteur clé de la construction de la République des Lettres. L'exemple étudié relève du cadre de la poésie sévillane de la seconde moitié du $X V I I^{e}$ siècle. Le litige se produit après la publication par Fernando de la Torre Farfán de son Templo panegírico (1663). Les arguments des rivaux permettent de faire des recherches dans la mentalité et les centres d'intérêt de la minorité lettrée de la ville, dans le cadre de son action au service des institutions qui la régissent.

Mots-clés : Torre Farfán, Torre Peralta, Solís y Valenzuela, Polémiques littéraires, république des Lettres.

Las polémicas entre escritores son un factor clave en la construcción de la República de las letras. Se estudia aqui un caso de la segunda mitad del XVII en el ámbito de la poesía sevillana. El litigio se produce tras la publicación por parte de Fernando de la Torre Farfán de su Templo panegírico (1663). Los argumentos de los contendientes permiten indagar en la mentalidad e intereses de la minoría letrada de la ciudad, en el marco de su actuación al servicio de las instituciones que la regían.

Palabras claves : Torre Farfán, Torre Peralta, Solís y Valenzuela, polémicas literarias, república de las letras.

Controversies between writers are a key factor of the building of the Republic of Letters. The example studied falls within the field of the second half of the seventeenth century poetry in Seville. The dispute happened after the publication of the "Templo panegírico"

\footnotetext{
* Este trabajo se inscribe en las tareas del proyecto i+d El canon de la lírica áurea: constitución, transmisión e historiografía (III) (FFI2011-27449), financiado por el Ministerio de Economía y Competitividad.
} 
by Fernando de la Torre Farfán (1663). The rival's arguments allow us to carry out research into the mentality and centers of interest of the town's learned minority, within the context of its action in the institutions that govern it.

Keywords: Torre Farfán, Torre Peralta, Solís y Valenzuela, literary Controversies, Republic of Letters.

L a figura del sacerdote sevillano Fernando de la Torre Farfán (1609-1677) brilla con luz propia en la neblinosa terra incognita que es todavía la literatura sevillana de la segunda mitad del XVII. En lo esencial, su producción está centrada en dos causas político-religiosas en las que la ciudad se empeñó a lo largo de la centuria. Una es la inmaculista, la otra la santificación del rey Fernando III $^{1}$. Las dos dieron fruto en la segunda mitad de siglo: breve de Alejandro VII, el 8 de diciembre de 1661, confirmando la doctrina de la Concepción sin mancha de María; decreto de canonización de Clemente X (febrero de 1671). Las dos fueron ocasión en Sevilla de celebraciones con las que la ciudad quiso expresar su regocijo y a la vez reivindicar su papel de protagonista en unos procesos que excedían la dimensión estrictamente ciudadana para afectar al prestigio de la Monarquía Hispánica en el orbe católico. Y ahí, en el marco de esos festejos, es donde Torre Farfán asienta sus reales, poniendo su pluma al servicio de las instituciones religiosas que se encargaron de organizar los correspondientes y fastuosos triunfos sacros, conforme a la acrisolada tradición de la ciudad ${ }^{2}$. El fruto de esos empleos fueron tres libros: el Templo panegírico $(1663)^{3}$, las Fiestas que celebró la Iglesia

1. Aunque referido a su arranque, el alcance de la causa inmaculista en Sevilla queda perfectamente enfocado en el trabajo de José Antonio Ollero Pina, «Sine labe concepta: conflictos eclesiásticos e ideológicos en la Sevilla de principio del siglo XVII», en Carlos Alberto González Sánchez y Enriqueta Vila Vilar (eds.), Grafías del imaginario. Representaciones culturales en España y América (siglos XVI-XVIII), México, Fondo de Cultura Económica, 2003, p. 336-352.Y sobre la dimensión nacional y local de la otra causa, véase Antonio Álvarez-Ossorio Alvariño, «Santo Rey. La corte de Felipe IV y la canonización de Fernando III», en Marc Vitse, ed., Homenaje a Henri Guerreiro. La hagiografía entre historia y literatura en la España de la Edad Media y del Siglo de Oro, Madrid, Iberoamericana / Franckfurt am Main, Vervuert, 2005, p. 243-260.

2. José Jaime García Bernal, El fasto público en la España de los Austrias, Sevilla, Universidad de Sevilla, Secretariado de Publicaciones, 2006, esp. p. 281-288 («Fiestas de exaltación doctrinal. Inmaculada. Corpus. San Fernando»).

3. Templo panegirico, al certamen poetico, que celebro la Hermandad insigne del Smo. Sacramento, estrenando la grande fabrica del Sagrario nuevo de la Metropoli sevillana, con las fiestas en obsequio del Breve concedido por la Santidad de N. Padre Alexandro VII al primer instante de Maria Santissima Nuestra Señora sin pecado original, que ofrece por Bernabe de Escalante, en nombre de la insigne Hermandad, al Ilustrissimo, y Reverendissimo señor Dean y Cabildo de la S. Iglesia Cathedral, y Patriarchal D. Fernando de la Torre Farfan. Con licencia, impresso en Sevilla, por Iuan Gomez de Blas, Impresor mayor. Año de 1663. Bernabé de Escalante y Osorio (n. en Sevilla, 1610) era en ese momento Alcalde segundo de la Hermandad sacramental y también pertenecía a la de las Ánimas del Sagrario, que colaboró asimismo en la celebración. Torre Farfán lo menciona varias 
Parrochial de S. Maria la Blanca (1666) ${ }^{4}$ (ambos de temática concepcionista) y el más conocido de todos, por su excepcional calidad tipográfica: las Fiestas ... al nuevo culto del Señor Rey S. Fernando (1672)5.

Estas y otras publicaciones nos dan una idea clara de la nombradía alcanzada por Torre Farfán en vida. El cronista Diego Ortiz de Zúñiga nos lo confirma dedicándole unos encarecidos elogios en sus Anales ${ }^{6}$. Y esa notoriedad perduró algún tiempo después de la muerte del escritor, como se comprueba en el ms. 58-2-25 de la Biblioteca Colombina y Capitular de Sevilla, que fue recopilado por el canónigo Diego Ignacio de Góngora (1628-1710), amigo del autor, y cuyo título principia: Poesías de Don Fernando de la Torre Farfán, insigne poeta sevillano ${ }^{7}$. El códice contiene básicamente: a) una noticia bio-bibliográfica de

veces en el libro, señalando su participación destacada en la organización de los festejos. Todo indica que costeó o contribuyó a costear el volumen.

4. Fiestas que celebro la Iglesia Parrochial de S. Maria la Blanca, Capilla de la Sta. Iglesia Metropolitana, y Patriarchal de Sevilla. En obsequio del nuevo Breve concedido por N. Smo. Padre Alejandro VII en favor del purissimo mysterio de la Concepcion sin Culpa Original de Maria Santissima Nuestra Señora, en el Primero Instante physico de su Ser. Con la circunstancia de averse fabricado de nuevo su Templo para esta fiesta. Dedicase a la Augusta Blanquisima Señora, por el postrado afecto de un Esclavo de su Purisima Concepcion. Colofón: Con licencia. En Sevilla, por Iuan Gomez de Blas, su impresor mayor. Año de 1666. Como se ve, el nombre de Torre Farfán no figura en la portada, pero sí aparece en el interior del volumen, p. 175, en el encabezamiento de la segunda parte del libro, un largo romance titulado Descripcion panegirica de esta insigne Fiesta, por Don Fernando de la Torre Farfan, cuya es la Relacion antecedente.

5. Fiestas de la S. Iglesia Metropolitana, y Patriarcal de Sevilla, al nuevo culto del Señor Rey S. Fernando el Tercero de Castilla y de Leon. Concedido a todas las Iglesias de España, por la Santidad de Nuestro Beatissimo Padre Clemente X. Ofrecelo a la Augustissima Magestad de Don Carlos II N. S. Rey de las Españas, la misma Santa Iglesia. Y escriviolo de orden tan superior, Don Fernando de la Torre Farfan, Presbytero, Natural de Sevilla. Con licencia. En Sevilla. En casa de la viuda de Nicolàs Rodriguez, este año de 1671. La fecha de la portada ha de corregirse con la de 1672 que aportan los preliminares. Hay ed. facsímil con introducción de Antonio Bonet Correa, Sevilla, Fundación Fondo de Cultura de Sevilla, 1985; y otra al cuidado de Sagrario López Poza, con introducción de Santiago Sebastián López: La Coruña, Euringra, 1991. Véase asimismo Isabel Balsinde Rodríguez y Marta Sáenz Bascones, «Un Torre Farfán en la Biblioteca de Palacio», Reales Sitios, no 121 , tercer trimestre, 1994, p. 38-45. Las citas de la obra (en adelante: TP) se hacen sobre el ejemplar 088/078 de la Biblioteca Universitaria de Sevilla, conforme a estos criterios: se moderniza la acentuación y la puntuación; se regulariza el uso de las mayúsculas; se regulariza el uso de $u$ vocálica y $v$ consonántica; se desarrollan las abreviaturas.

6. Anales ecclesiásticos y seculares de la muy noble y muy leal ciudad de Sevilla ... que contienen sus más principales memorias desde el año de 1246... hasta el de 1671..., Madrid, Imprenta Real, 1677 (pero cito por la de Madrid, Imprenta Real, 1795-1796). Así lo llama «noble y erudito hijo de esta ciudad» (V, p. 159), o pondera «la agudeza de su ingenio, la propiedad de su estilo, y lo grande de sus estudios» (V, p. 237).

7. El título, completo y normalizado, es: Poesías de Don Fernando de la Torre Farfán, insigne poeta sevillano, copiadas de los originales del autor y algunas que tenia en la memoria dictadas por él mesmo (292 h., en 40). El monograma del recopilador figura tanto en la parte superior de la portada como al final del prólogo. Este fue redactado después de 1685, pues en él se menciona la muerte ese año del también canónigo D. Justino de Neve, que fue el heredero de los papeles de Torre Farfán. Todo lo cual ratifica sus estrechas relaciones con el selecto cabildo catedralicio. Seguramente se trata del mismo códice que aparece registrado en el Catálogo de manuscritos del conde del Águila, Biblioteca Universitaria de Sevilla, 331/198, f. 50r. 
Torre Farfán redactada por el recopilador ${ }^{8}$; b) una colección de sus poesías, así como una comedia impresa (Las tres noches de la quinta) ${ }^{9}$; c) una serie de textos de autoría diversa, unos en prosa, otros en verso, derivados de la publicación del Templo panegírico. De estos últimos, todos menos uno dan cuenta de una polémica que siguió a dicha publicación y que será el tema principal de este trabajo $^{10}$.

8. La reprodujo Juan G. Cívico de Porres en Poesías de D. Fernando de la Torre Farfán 16091677, Sevilla, Tip. Gironés, 1915, p. 9-12 (una versión algo distinta de dicha semblanza figura en las adiciones que Diego I. de Góngora hizo a los Varones insignes en letras de Rodrigo Caro: Biblioteca Colombina y Capitular, ms. 59-1-1, f. 208r-211r). Por ahí sabemos que su gran afición a las letras le valió convertirse en una especie de arbiter elegantiae entre «los caballeros y títulos de esta ciudad», en la que también fue conocido por su facilidad para componer versos y por su activa participación en la organización de justas poéticas de carácter devoto, especialmente de tema mariano. Entre sus obras inéditas cita Góngora un Laurel de Apolo, «libro para introducir el Certamen Poético a el Misterio de la Purísima Concepción que se celebró en el Alcázar de esta ciudad el año de 1653», festejo del que conservamos algunas noticias fragmentarias en el propio Templo panegírico (donde se identifica al citado escrito como Laurel panegírico de España) y una copia manuscrita de las leyes de la justa (véase Rogelio Reyes, «Fernando de la Torre Farfán, un animador de justas poéticas en la Sevilla del XVII", Dicenda, n 6, 1987, p. 501-507; y Luis Miguel Godoy Gómez, Las justas poéticas en la Sevilla del Siglo de Oro, Tesis doctoral, dir. Rogelio Reyes Cano, Universidad de Sevilla, curso académico 2000-2001, p. 275-280.). Con posterioridad han sido sobre todo los historiadores del arte los que se han interesado por la figura de Farfán, subrayando sus conocimiento en la materia, su más que posible vinculación con la academia del pintor Murillo y su colaboración con los pintores y grabadores sevillanos del momento; véase lo que apuntan al respecto tanto A. Bonet Correa como S. Sebastián López en la introducción de sus respectivas ediciones de las Fiestas ... al nuevo culto del Señor Rey S. Fernando, p. XV-XVIII y VII-X, respectivamente. Y también son de interés las referencias contenidas en varios de los trabajos recogidos ahora en Gabriele Finaldi, ed., Murillo y Justino de Neve. El arte de la amistad, Madrid - Sevilla - Londres, Museo Nacional del Prado, Fundación Focus-Abengoa, Dulwich Picture Gallery, 2012 (remito al índice de nombres).

9. De ahí proceden las que publicó Cívico de Porres. En cuanto a la producción dramática, Cayetano A. de la Barrera le atribuye un número indeterminado de piezas dramáticas, entre las que identifica, además de la ya mencionada, otras dos comedias: Dama, galán y fantasma, y Valor, ingenio y firmeza, o Diego Paredes (Catálogo bibliográfico y biográfico del teatro antiguo español, Madrid, Rivadeneyra, 1860, p. 399b). En la Biblioteca Nacional se conserva una copia manuscrita de Las tres noches de la quinta (ms. 16987) y otra de un auto sacramental: Los sentidos corporales (ms. 23110).

10. El texto del que aquí no me ocuparé está remitido a Farfán por un monje jerónimo de San Isidoro del Campo (Santiponce, Sevilla), fr. Andrés de Lillo y Villamanrique, con fecha del primero de agosto de 1662. Ocupa los f. 172r-202r del códice capitular y contiene una defensa de la dignidad de la poesía (sobre el trasfondo de que las letras humanas están al servicio de las divinas), rematada con seis composiciones que se corresponden con las seis secciones que tuvo la justa del Sagrario. Del autor y de su escrito se ocupa Luis Miguel Godoy Gómez, Tesis doctoral, cit., p. 815-825; y del mismo: «Poetas perseguidos: una contribución a la historia española de la infamia", Los papeles mojados de río seco, 8, 2009, p. 29-34, espec. p. 30-32. El padre Lillo es asimismo el autor de una Descripción prosi-poética del convento de monjes de San Gerónimo de Guisando... (Sevilla, 1662). Véase David Ferrer, Avila y la literatura del barroco (1582-1700), Ávila, Diputación, 2004, p. 141-157; y Fernando R. de la Flor y David Ferrer, «Ecología sacra. Unas soledades eremíticas: Andrés de Lillo y su Descripción prosipoética de San Jerónimo de Guisando y sus cuevas", en El siglo de Oro en escena. Homenaje a Marc Vitse, coord. Odette Gorsse y Frédéric Serralta, Toulouse, PUM/consejería de Educación de la Embajada de 
Antes de entrar en materia es preciso hacer una somera explicación de la naturaleza y contenido del libro que tanto revuelo causó. Para lo cual hay que remontarse al origen de la fiesta, que no es otro que el breve Sollicitudo omnium ecclesiarum, en el que Alejandro VII hacía la defensa expresa de la doctrina inmaculista, prefigurando su futura definición dogmática, al tiempo que destacaba las numerosas peticiones y gestiones que habían realizado en ese sentido tanto la Iglesia como la Monarquía de España. En Sevilla, la noticia desencadenó una oleada festiva cuyo primer embate culminó con la consagración de la nueva parroquia del Sagrario, templo anexo a la Catedral. La construcción de la iglesia estaba muy avanzada, aunque no terminada en 1661, de tal manera que cuando en junio de 1662 se llevaron a cabo los festejos hubo que levantar unos retablos efímeros tanto en el altar mayor como en los del crucero. Iniciada la celebración el jueves 15 de junio, festividad del Corpus, esta culminó con el certamen poético, cuyo secretario fue Torre Farfán, y que, aunque estaba prevista para el 29 de dicho mes, finalmente se celebró el domingo 9 de julio, con gran participación de ingenios ${ }^{11}$.

La preparación del libro le llevó unos pocos meses a Torre Farfán, pues su aprobación está fechada a tres de febrero de 1663 . El volumen, de 272 hojas más 14 de preliminares, arranca con la relación de la fiesta (f. 1-27r) en la prosa altisonante que se había hecho habitual para tales ocasiones. Viene luego una extensa relación del certamen, rotulada con la estruendosa portadilla que sigue y que reproduce parcialmente el cartel anunciador:

Palestra superior a el ingenio, Iusta poética y iustíssimo ardor que aliente las Musas Béticas que, del papa Alejandro VII depuestos los ardores profanos, vistan sagrado el arnés del Sol, en aplausos numerosos de la gloria de María Santíssima, por la expedición del Breve que la Santidad de Alexandro VII concedió a favor de su Concepción sin mancha. A cuya ingeniosa contienda apercibe la Illustre Hermandad Sevillana de el mayor sobre los augustos Señor Sacramentado en el Solio de su Sagrario Nuevo, estrenando sus limpias Aras con tan siempre cándido culto, después de trasladar en ellas sus blancas Sacramentales Especies ${ }^{12}$.

España en Francia, 2006, p. 881-892.

11. El libro de Torre Farfán es la principal fuente de información sobre el festejo, junto con los Anales de Ortiz de Zúńiga. Luego se han ocupado de él, entre otros, Manuel Serrano Ortega, Glorias sevillanas, Sevilla, E. Rasco, 1893, p. 531-538; Teodoro Falcón Márquez, «Procesión con motivo del estreno de la iglesia del Sagrario. Documento pictórico del entorno de la Catedral de Sevilla en 1662", Laboratorio de Arte, 12, 2000, p. 143-152; y Ma. Jesús Sanz Serrano, Fiestas Sevillanas de la Inmaculada Concepción en el siglo XVII, Sevilla, Ayuntamiento de Sevilla - Universidad de Sevilla, 2008, p. 172-180. En cuanto a la relación de la justa propiamente dicha, contamos con el concienzudo estudio de Luis M. Godoy Gómez, en su Tesis doctoral, cit., especialmente, p. 283-294 (índice de composiciones impresas en el TP), 937-988 (estudio de la relación del certamen por Torre Farfán). Algunas alusiones hay también en la publicación derivada de la tesis: Las justas poéticas en la Sevilla del Siglo de Oro. Estudio del código literario, Sevilla, Diputación provincial, 2004.

12. El anuncio queda presentado así al final de la relación precedente (f. 27r): «Tiempo avía, aunque limitado, que estaba pregonada la guerra ingeniosa, para que las Musas sagradas previniessen los arneses doctos. Teníalo apercibido un cartel, ostentosse a tal contienda en todas las publicidades hispalenses. Intimose, además, a las distantes plumas que quisiesen volar a tan 
Esta parte, escrita en una prosa más concisa y trufada de continuos juegos de ingenio, incluye la publicación de 83 poemas, correspondientes a 42 autores, cantidad que solo constituye, como solía ocurrir, una parte de los presentados al concurso. Los textos van repartidos en seis secciones o templos, cada una de las cuales aborda un asunto planteado como la cristianización de un conocido templo de la antigüedad pagana o al menos de un episodio con él relacionado (así, en la última sección, el incendio del templo de Artemisa en Éfeso vale como figura del fallido intento del Diablo por dańar el templo de la pureza inmaculada de María) ${ }^{13}$. Las formas poéticas propuestas son: canción (según el esquema métrico de la gongorina que empieza «Por este culto bien nacido prado»), soneto, octavas, romance, glosa de una redondilla y vejamen a un diablo en sextillas de pie quebrado. Por lo demás, no faltan aquí otras piezas habituales en este tipo de textos, como las cédulas jocosas, la oración introductoria o el consabido vejamen como cierre de la justa (f. 243v-246v).

Ahora bien, este apretado resumen deja fuera un par de características literarias que singularizan al libro de Torre Farfán. La primera es que la relación del certamen se hace mediante una invención poética de aire lucianesco y que moviliza diversos tópicos relacionados con la autorrepresentación del poeta en el marco de la naciente república literaria ${ }^{14}$. Prácticamente toda la relación aparece inserta en el marco de un sueño en el que Torre Farfán, secretario de la justa, realiza un imaginario viaje hasta el Parnaso, donde se encuentra con Apolo y las Musas, quienes, entre chanzas, le prestan su colaboración para que el concurso se desarrolle como es debido (e insisto: dentro del propio sueńo se hace la relación del certamen). Tal ayuda, con todo, no es desinteresada: Apolo (¡que es un devoto de la doctrina inmaculista!) quiere aprovechar la ocasión para dar de baja en su Parnaso a los poetas paganos antiguos y sustituirlos por los modernos que concurren al certamen ${ }^{15}$. La segunda peculiaridad es que, salvo un par de excepciones que se justifican, todas y cada una de las composiciones de la justa recogidas en el libro van seguidas de un vejamen en forma de

grave palestra. La trompa que concitava su métrico trance es la que suena con el rumor siguiente.»

13. El artificio responde a una tendencia que se había ido asentando en las justas poéticas a lo largo de la primera mitad de siglo: "Incluso los carteles de convocatoria se impregnan ocasionalmente de este espíritu artificioso, que unas veces puede manifestarse en la alambicada prosa retórica de su introducción y otras en el ingenio de cohesionar los asuntos dentro de una serie de correspondencias simbólicas, como las sibilas que articulan los requerimientos en la justa salmantina a Santa Teresa [1614], las joyas y las piedras preciosas en la justa mallorquina a Sor Catalina Tomasa [1625], o los signos del zodíaco y los planetas en la dedicada a San Ignacio y San Francisco Javier en Madrid [1622], entre otros casos» (Inmaculada Osuna Rodríguez, «Las justas poéticas en la primera mitad del siglo XVII», en Begoña López Bueno, ed., El canon poético en el siglo XVII, Sevilla, Universidad de Sevilla - Grupo PASO, 2010, p.337).

14. Véase al respecto el planteamiento que se hace en El Parnaso versificado. La construcción de la república de los poetas en los Siglos de Oro, ed. Pedro Ruiz Pérez, Madrid, Abada, 2010.

15. Para ello Torre Farfán va adjudicando a cada participante en la justa el nombre y lugar de uno (o a veces dos) de los autores antiguos. Más allá de la preferencia por dar a sus amigos algunos de los nombres más ilustres, el reparto se hace, en general, a voleo o por razones puramente anecdóticas. 
romance, rematado con un epigrama latino y su correspondiente traducción ${ }^{16}$. No conozco ningún caso de otra justa impresa que contenga tantos vejámenes como poemas del certamen ${ }^{17}$. Extrańa y hasta maniática rareza que bien que se le reprocha a Torre Farfán, además de otras cosas, en la jocosa carta titulada Xícara de chocolate, cuyo autor dice ser un monje jerónimo (otro) del ya citado convento de San Isidoro del Campo que había participado en la justa ${ }^{18}$.

Así que la invención poética del Templo panegírico viene a resaltar de manera algo paradójica el papel del secretario Torre Farfán: a primera vista el sueño lo coloca en una posición humorística de incapacidad y, a la vez, de total subordinación a los dictados de Apolo y de las Musas. Pero en realidad esto implica la sublime experiencia de haber alcanzado el Parnaso y departido con sus moradores, a los que da voz en el libro. Todo el aparato mitológico que rodea el certamen ha salido, pues, de la fantasía del Secretario y, de hecho, su presencia es total, tanto en su condición de relator (aunque es verdad que la narración, tras arrancar en primera persona, pasa luego a la tercera) como en la de autor de los vejámenes que siguen a los poemas, piezas que seguramente compuso ex professo para el libro. Como remate de la faena, una vez finalizada la relación del concurso, pero todavía dentro del sueño, incluye seis composiciones suyas conforme a las seis secciones del certamen, acompañadas nuevamente de sus correspondientes vejámenes.

Todo indica, en definitiva, que Torre Farfán ha asumido su condición de relator del certamen como un reto y una oportunidad de mostrar tanto su erudición (que, en efecto, no era escasa) como su inventiva literaria. $\mathrm{O}$ sea, que ha querido mostrarse como un verdadero autor. Y esta impresión queda confirmada por la lectura de los copiosos preliminares del libro, que

16. Torre Farfán toma esos epigramas, que luego traduce, de otros autores, especialmente de Marcial y de John Owen. Lo segundo es relevante, ya que tales versiones se imprimieron antes de que Francisco de la Torre Sevill sacase a luz las suyas: Agudezas de Juan Oven traducidas en metro castellano, Madrid, por Francisco Sanz, en la Imprenta del Reyno, 1674.

17. Cabe pensar que hay un vínculo entre la abundancia de vejámenes y la adopción del marco onírico en la relación de Torre Farfán, ya que ambas modalidades se venían asociando a lo largo del XVII, quizá como una manera de establecer un mecanismo de distanciamiento que hiciese menos hiriente la burla. Véase ahora el estado de la cuestión y la bibliografía que ofrece Abraham Madroñal, De grado y de gracias. Vejámenes universitarios de los Siglos de Oro, Madrid, CSIC, 2005. La obra incluye (p. 427-454) la edición de un vejamen de Torre Farfán en unos Grados en el Colegio de Santa María de Jesús (1655). El texto se conserva en un ms. que también copió Diego Ignacio de Góngora (Real Academia Española, R-M 6877). Sobre el recurso del sueño, véase Teresa Gómez Trueba, El sueño literario en España. Consolidación y desarrollo del género, Madrid, Cátedra, 1999, esp. p. 87-126 («Los sueños literarios en el siglo XVII»).

18. Hay una copia en el ms 3891 de la Biblioteca Nacional, códice que curiosamente está recopilado por el hijo de otro concursante de la justa, el médico de origen portugués Duarte Núñez de Acosta, gran admirador de Farfán (véase más abajo la n. 36). De la lectura del texto se deduce que el autor podría ser fray Jerónimo de Arce, quien, pese a ser ganador de un primer premio en la justa, expone puntos de vista bastante críticos sobre el libro y su autor. Me ocupo de este escrito, que es como una rama menor de la polémica aquí abordada, en "Xícara de chocolate contra Torre Farfán y su Templo panegírico (Sevilla, 1663)», Manuscrt.Cao, 13 (2012). http:// www.edobne.com/manuscrtcao/xicara/ 
incluyen, además de las piezas legales (aprobación y licencia) o convencionales (dedicatoria, poemas preliminares) una imprevista y muy interesante "Censura crítica» a cargo de su amigo Cristóbal Bánez de Salcedo, en la que encontramos indicaciones sobre los primores del estilo del autor, sobre lo acertado de sus traducciones o sobre la galanura de «una idea cuya fantasía está llena de muy hermosa invención poética y cuya falta causara mucho desaliño", refiriéndose al marco narrativo en el que se inserta la relación del certamen ${ }^{19}$. Por si faltaba algo, entre esos preliminares hay dos grabados calcográficos ejecutados por Matías de Arteaga, uno ubicado al principio, por delante del frontispicio, y otro cerrando los preliminares, tras la fe de erratas ${ }^{20}$. El primero representa, en escala ascendente, una vista panorámica de la ciudad de Sevilla, el lema NO\&DO, el templo del Sagrario y la Giralda, entre la insignia eucarística y la inmaculista, engalanada con la leyenda: TEMPLO Panegirico. La idea es que el libro vale por un templo que Sevilla y su Iglesia ofrecen a la mayor gloria de María y de Jesús sacramentado, sin que pueda descartarse que el autor (Torre, al fin y al cabo) esté autorrepresentándose en la imagen de la Torre Mayor de Sevilla, mediante una especie de metonimia icónica. El segundo grabado muestra el busto del propio Torre Farfán en un óvalo entre coronas de laurel, clarines de la Fama y otros instrumentos; como remate, también entre laureles, un escudo de armas (seguramente el suyo) y, en la parte inferior, un epigrama latino que viene a proclamar que su nombre resuena ya por todo el orbe. No es exagerado decir, por tanto, que en el libro funciona una estrategia de (auto) canonización por parte del autor y de sus amigos. Y ese fue sin duda un factor determinante en la polémica que siguió a la publicación ${ }^{21}$.

Para informarse sobre ella, nada mejor que volver al ya citado ms. 58-2-25 de la BCC, f. 203r-204v, porque ahí se contienen la totalidad de las piezas que la componen, precedidas de una presentación redactada por Diego Ignacio de Góngora. Dice así (van en cursiva las palabras subrayadas en el ms.):

En el libro que imprimió la hermandad de el santísimo Sacramento, sita en el Sagrario de la santa Iglesia Metropolitana y Patriarchal de Sevilla, de el certamen y justa poética que se hizo en él quando se colocó el santísimo Sacramento en el templo nuebo el año de 1662, y dispuso y ordenó don Fernando de la Torre Farfán, Secretario de la justa, se puso un retrato del autor a el principio del libro, orlado en lugar de tarja con un laurel, y otros adornos e instrumentos del intento del libro. Entre otros poetas, escribió en el certamen don Joseph Román de la Torre y Peralta a algunos assumptos; sus poesías no devieron de conseguir el premio que él juzgaba merecían,

19. De Báñez Salcedo, que debe ser hijo de Da. Andrea de Salcedo y de D. Cristóbal Báñez Artazubiaga, médico de S. M., vecino de Sevilla, sabemos que participó, en compañía de Torre Farfán, en algunas academias poéticas sevillanas en la década de los 60. En el Templo se recogen dos composiciones suyas, que no optaban a premio: una canción (f. 64v) y un soneto (f. 96v). Según las noticias biográficas que las acompañan estudió en Salamanca y fue militar, o por lo menos tuvo alguna actividad en ese campo.

20. Al menos así figuran en el ejemplar de la Biblioteca Pública del Estado en Orihuela, sign.: 8980 , que es uno de los raros que conserva ambos grabados y que, además, está digitalizado en la Biblioteca virtual del patrimonio bibliográfico.

21. Hasta ahora solo la ha estudiado Luis M. Godoy Gómez, Tesis doctoral, cit., p. 988-1036. 
con lo qual quedó disgustado y, viendo que en el libro, al referir sus poesías, en el vexamen le avían sacado a público la habilidad de que sabía pintar (como si fuera este agrabio contra su pundonor, siendo un arte tan noble y que le exercitan Príncipes y señores de primera magnitud) se sintió desto como del vexamen, ignorando quiçás el estilo usado en las escuelas y Universidades y en los certámenes. [203v] Con esta queja fue a un religioso cartujo del monesterio de las Cuebas de Sevilla, grande amigo y favorecedor suyo, y también lastimado porque no se devió de hazer aprecio de sus versos ni de unas estampas que avía impreso en forma de cartas que, desdoblándolas, se vían diferentes formas y figuras, con sus coplas y versos a los intentos que el religioso pretendía. Y como halló del proprio humor al consejero, dispuso un papel de quatro pliegos que intituló: Festín de las tres Gracias en celebridad del primer instante puro de María santíssima concebida sin mancha. Vexamen al Demonio y a un Poeta que se laureó a sí mismo, y se imprimió en Sevilla el año de 1664, poco después de aver salido el libro Templo Panegérico [sic], que dicho don Fernando de la Torre dispuso con las poesías de el certamen; y en él por prólogo o exortación escribió unos versos indignos de que se permitiesen dar a la imprenta ni que se publicasen, assí por lo que tocaba al sugento $[s i c]$ venerable de don Fernando como por ser fuera de la verdad lo que en ellos dize, dedicando su obra con grandes alabanzas, epítetos y elogios a el proprio religioso cartuxo su gran amigo, [204r] cuio exemplar, como salió entonces, es el que va aquí puesto. Irritó grandemente esta desmesura a los amigos de don Fernando y se puede dezir que a los principales hombres de la ciudad, si ya no fuese a toda ella, por lo bien quisto que estaba en ella, y por sus méritos y ciencia, que publican bastantemente las obras y escritos de don Fernando, venerado por su dignidad y por su sangre, tan notoria y conocida en Sevilla. Y llegó a tanto el afecto que los carteles que pusieron en las esquinas dando noticia del papel, su autor y dónde se vendía, públicamente de día los hizieron pedaços, y pasaron a casa del librero y le quitaron sus amigos los papeles, pagándole su costo, en demostración del enfado que avía causado y escándalo que se avía dado con él. Dixéronle muchas injurias al don Joseph Román de la Torre, y algunos de los amigos de don Fernando, irritado, encontrándole en calle de Abades, sacó la espada contra él, y la interposición de las personas que acaso lo vieron, le libró deste peligro, con que, atemorizado, no pareçió en muchos días, [204v] y le obligaron a que pidiese perdón a don Fernando con muestras de mucha sumisión, pero no obstante, mientras esto suçedió, se escribieron los papeles que aquí van y instaron a don Fernando de la Torre escribiese en su defensa (aunque él quería despreciarlo) y escribió la Torre del Templo que también va en este volumen.

El retrato que dio ocasión a la detracción de D. Joseph Román de la Torre y Peralta y se puso al principio del libro Templo Panegírico, es el que va puesto al principio deste volumen.

Ya tenemos ahí a los tres protagonistas principales de la polémica: Torre Farfán, de un lado, y de otro, José Román de la Torre y Peralta junto con un cartujo anónimo (por ahora) del monasterio de Santa María de las Cuevas, a las afueras de Sevilla. Pero su nombre sale a relucir en cuanto nos asomamos a la portada del texto que encendió los ánimos y que, seguramente por circular impreso, alcanzó notable impacto en el mundillo literario sevillano: el Festín de las tres gracias (Sevilla, 1664) ${ }^{22}$. Como se ve por el inacabable rótulo de la

22. La portada al completo dice así: Festin de las tres gracias, en celebridad del primer instante puro de Maria Santissima concebida sin mancha. Vexamen al demonio, y a un poeta que se laurè a si mismo. Recuperacion de lo proprio, que por suyo vendió la malicia. Restitucion de lo ageno, que usurpò el error o la ignorancia. Por D. Ioseph Roman de la Torre y Peralta. Dedicalo al mas azerrimo defensor de la mas intacta Virgen. Al zelo mas fervoroso de su Concepcion purissima. Al verdadero 
portada, la publicación presenta una doble cara. La más aparente es la de un escrito (un poema, de hecho) inmaculista, pero a renglón seguido se introducen unas cuestiones más terrenas, que van dibujando los perfiles de una guerra literaria: se anuncia el vejamen "a un poeta que se laureó a sí mismo» y se reivindica para el cartujo Fray Bruno Solís de Valenzuela la verdadera autoría de cierto escrito, nuevamente inmaculista, publicado en Sevilla el año de 1663 (de esto se trata más abajo). El autor que asume la responsabilidad del Festín es José Román de la Torre y Peralta, del que lo primero que debemos saber es que había participado en el certamen de 1662 sin recibir ningún premio y que dos composiciones suyas aparecen recogidas en el Templo Panegírico: unas octavas (f. 143r) y una glosa (f. 200v). El único dato biográfico que se trasluce de los vejámenes y de los comentarios que Apolo y las musas intercambian sobre este concursante es que era pintor aficionado, aunque procuraba ocultarlo (de pintor vergonzante, se le tilda en el segundo vejamen ${ }^{23}$.

Los elementos de polémica literaria se concentran en dos poemas que forman parte del primer pliego de la publicación y que, según todos los indicios, no constaban en el original remitido al Arzobispado de Sevilla para su aprobación y licencia. El primero es un Prologo o exortacion, a los que leyeren Legos, o doctos, que en forma de romance contiene un ataque apenas velado contra el Templo Panegírico y su autor. Además de criticar su estilo pesado y falto de gracia, le echa en cara el carácter satírico (y no meramente festivo) de los vejámenes así como que para ellos haya tomado en préstamo los versos de Marcial y de John Owen. Una buena parte del romance está dedicada a mostrar la indignación y la risa que le ha causado a Peralta la presencia en el libro del retrato de Torre Farfán. El libelista le reprocha a su oponente que no puede considerarse autor, pues en su obra se ha limitado a recopilar lo que han escrito otros. Y que en cualquier caso, un poeta no puede coronarse a sí mismo, sino que ha de recibir la corona de manos ajenas. Al final saca Peralta a relucir otro asunto: que el ignorante de Torre Farfán ha atribuido a un cartujo de nombre Francisco Ximénez una obra que en realidad pertenecía al ya nombrado Solís y Valenzuela, del que hace un breve pero encendido elogio. La restitución a su dueño de esa pieza inmaculista es también el motivo de arranque del segundo romance, que lleva por título

único y legitimo autor, de la ingeniosissima estampa de su triumpho inmaculado, que en abiertas laminas publicó Sevilla. Año de 1663. El M.R.P.D. Fray Bruno de Solis Valenzuela monxe profeso de la Real Cartuxa del Paular de Segovia, y natural de Santa Fè del nuevo Reyno. Con licencia. Impresso en Seuilla, por Miguel de Aldabe. Año de 1664. Son 14 hojas en 4º, con aprobación de 12 de enero de 1664 y licencia del 15. Lo de las Tres Gracias del título se explica porque el poema pone en escena a tres ninfas, cada una de las cuales entona un canto en honor de María y luego otro las tres al unísono. Dichos cantos se engarzan en una narración que incluye asimismo la écfrasis de un impreso poético que debe ser el mismo que se nombra en la portada. Llama la atención que algunas de las piezas que forman el polimétrico Festín guarden cierta similitud con las que se pedían en el certamen de 1663: sextillas de pie quebrado contra el diablo (B2v), romance dando vaya al diablo (B4r).

23. Los textos de la polémica, por su lado, sí que aportan algunos detalles interesantes sobre la persona y la obra de Torre y Peralta, que al parecer tampoco era sevillano de origen. Los iremos mencionando a lo largo del trabajo. 
"Dedicatoria en forma de desagravio al más eloquente mudo», y que no hace sino remachar el clavo de la ignorancia o malicia de Torre Farfán en todo este asunto.

El tal Valenzuela era neogranadino, pues, como se indica en la misma portada del Festín, procedía de Santa Fe (de Bogotá), donde nació en 1616 y residió hasta su traslado a España ${ }^{24}$. Conocemos varias obras literarias suyas, pero ninguna de tanta importancia como una que se le atribuyó algún tiempo, pero que hoy se considera obra de su hermano Pedro, Desierto prodigioso y prodigio del desierto, que está considerada una pieza relevante dentro de la producción colonial y que, en efecto, contiene algunos poemas de Bruno ${ }^{25}$. Por el interés que tiene para la polémica, he intentado identificar y localizar la obra del cartujo que fue causa de discordia con Torre Farfán, pero esto no ha sido posible hasta ahora ${ }^{26}$.

Una pregunta obligada es la de cuál fue el papel exacto de Solís y Valenzuela en el Festín. Es evidente que Torre y Peralta no pudo actuar sin contar al menos con la venia del cartujo, si no fue con su aliento. Los demás textos de la polémica van más allá incluso, dando por hecho que fue el verdadero autor del escrito, afirmación que en efecto debe tener su parte de verdad, aun contando con las argucias argumentativas propias del género. Personalmente me inclino a creer que el Festín fue una obra a cuatro manos, cuya autoría habría que repartir de

24. Siendo ya sacerdote y doctor en Teología, se le encomendó el traslado a España, en 1638, del cadáver del Arzobispo de Santa Fe de Bogotá, don Bernardino de Almansa. En 1641 profesó en la Cartuja del Paular de Segovia, cambiando su nombre (Fernando) por el de Bruno; llegó a ser prior en la de Aniago (Valladolid) y pasó temporadas en las de Sevilla y Jerez, donde falleció en 1677. En la de Sevilla ejerció como secretario del prior Francisco de Loaysa y Chaves, que también fue visitador general de la Provincia de Castilla, y al que se le nombra en el Festín, D1r, como dedicatario del triunfo usurpado.

25. De hecho está representado en la obra en el personaje de D. Fernando. De la misma hay edición moderna: Pedro Solís y Valenzuela, El desierto prodigioso y prodigio del desierto, ed. Jorge Páramo Pamareda, Manuel Briceño y Rubén Páez Patiño, Bogotá, Instituto Caro y Cuervo, 1977-1985, 3 vols. Sobre el autor y sobre su hermano Fernando / Bruno hay cumplida información en la introducción del vol. I de la citada ed. y en Manuel Briceńo Jáuregui, Estudio histórico-critico de «El desierto prodigioso y prodigio del desierto» de Don Pedro de Solís y Valenzuela, Bogotá, Instituto Caro y Cuervo, 1983; especialmente p. 214-269 («Don Fernando [Fernández de Valenzuela, 1616-1677] »), que resumen la vida y obra del cartujo, aunque no mencionan para nada el asunto que aquí tratamos.

26. Ahora bien, la falta de ejemplares puede suplirse en parte con las alusiones a ese papel en el Templo Panegírico: «unos Hieroglíficos de vanderas y otras municiones» (f. 188r); «ideas imaginadas de sacras fantasías executadas en ingeniosíssimas estampas» (f. 189v); repárese en que estos elogios se hacen antes de la polémica y de que Valenzuela reclame la autoría de la pieza. Descripciones más detalladas del impreso y de su contenido encontramos en otras dos obras, si he entendido bien. Una es el propio Festín (f. C2v-D1v). La otra es la pieza de Gaspar Agustín de Lara y Lugo titulada: Idea panegirica de los dibuios, que contiene el Triumpho inmaculado de la Madre de Dios, Emperatriz del Cielo, y Tierra; concebida en Gracia, y Gloria desde el primero instante de su animado ser. Que delineo con nouedad ingeniosa, muda Eloquencia, Erudicion profunda .... Bruno de Solis y Valenzuela monje Cartuxano ... [S.l. : s.n., s.a.]. Según dice la portada, Lara y Lugo se tenía por «amigo, obligado siervo y rendido discípulo» de Bruno. Hay un soneto suyo entre los preliminares de El desierto prodigioso. 
algún modo entre Peralta y Valenzuela. Algo parecido habría que decir de las respuestas que recibió el Festín: según Diego Ignacio de Góngora, solo una de ellas es obra del propio Torre Farfán, pero cabe sospechar que su mano también interviene en las otras de manera total o parcial.

Eso es para mí evidente en la primera de todas, según el orden con que aparecen en el citado ms. 58-2-25, la titulada Azote de las Tres Furias ${ }^{27}$, un largo romance rematado al final con un soneto («Mísera torre que con vajo intento»). Sintéticamente, la argumentación que desarrolla el romance es esta. Peralta es autor interpuesto del Festín, ya que el verdadero es el cartujo, cuyo ingenio no da para más que unas baratijas literarias como el poema desplegable cuya autoría se reclama. El Templo de Farfán, en cambio, es una obra de gran mérito a la que no alcanza la censura, máxime si esta viene firmada por alguien como Peralta, ansioso por llevar a la imprenta cualquier ocurrencia con tal de ganar unos reales. Resulta increíble por ello que haya criticado la presencia del retrato de Farfán en el Templo, ya que esa es costumbre entre los escritores y que, además, la decisión de ponerlo no fue suya sino ajena (una nota marginal indica: «Fuelo de quien costeó la imprenta.»). Sea como fuere, Farfán reúne méritos sobrados para que su efigie figure en el libro entre clarines y laureles (aunque no coronado de ellos, como maliciosamente le achacan). Cuanto más que Valenzuela no debería hablar de retratos, ya que uno de su hermano Pedro, este sí: laureado, circulaba por Sevilla en un impreso reciente, sin que nadie sepa qué méritos tenía para ello ${ }^{28}$. Y qué retrato: ¡con una bolsa de dinero en

27. Ms. 58-2-25 de la Biblioteca Capitular (Sevilla), f. 219r-228v. El título completo es: Azote de las Tres Furias que saca à luz la verdad para Castigo de un atrevido Prologo que imprimio en Seui[Ll]a Año de 1644 la malicia de D[o]n Joseph dela Torre y Peralta que le prohija en vn papel intitulado Festin de las tres Gracias profanando el Venerable Templo Panegirico, de D[o]n Fernando dela Torre Farfan Seuillano Apolo en la lisonja, que dize su modestia, hizo el que imprimio el Libro poniendo en el su Retrato, tenida de todos por corta, mirando sus Meritos. Inc.: «Escucha eterno arrendajo, / poeta mono del pueblo». Además de esta conozco otras dos copias una que se conserva en la Biblioteca Nacional (ms. 23109) y otra en la Hispanic Society of America (cf. Antonio Rodríguez-Moñino y María Brey Mariño, Catálogo de los manuscritos poéticos castellanos existentes en la biblioteca de The Hispanic Society of America (siglos XV, XVI, XVII), Nueva York, Hispanic Society of América, 1965, n CCXXXI). Estas dos, después del título en su forma abreviada, presentan un subtítulo que induce a error: «Satyra contra el Templo Panegirico que escrivio D. Ferno de la Torre q[ue] anda impresso escrita por cierto monge». Las tres tienen la peculiaridad de llevar notas marginales que aclaran muchas de las alusiones que se hacen a lo largo del texto. A falta de un estudio más detenido, diría que la sevillana representa la versión definitiva, con algunas variantes.

28. El retrato, un grabado calcográfico, está incluido de hecho en el ms. capitular, f. 269r, en el marco del último de los escritos de la polémica, la Torre del templo. Su autor es el mismo Matías de Arteaga que hizo el de Farfán. Según una inscripción que figura en su parte superior, Pedro tiene una edad de 39 años y está representado de medio cuerpo, con la pluma en la mano derecha y con una bolsa de monedas, que está vaciando como limosnero, en la izquierda. Al pie lleva esta leyenda: «D. D. PETRVS DE SOLIS ET VALENCUELA / Presbiter Sancte fidei amore, reverentia, / et benefficentia erga Perentes seu fratrem / Cartusia sorores que Tobias iunior.» Está fechado en Sevilla, 1663. Imposible saber por ahora con qué motivo se hizo el retrato. Acaso en algún escrito que tuviese como tema la figura bíblica del joven Tobías, asunto al que sabemos que Bruno dedicó una obra hoy desconocida. 
la mano, como Judas! Así que Peralta tiene que estar loco para haber firmado un ataque nada menos que contra Torre Farfán, que si quisiera entrar en lid podría destruirlo, pero no lo hará por no abatirse a cosa tan vil. Porque ¿quién prestaría atención a un escrito de quien no tuvo reparo en saludar la venida a Sevilla de un hereje, el embajador de Inglaterra? ${ }^{29}$ La cosa está clara: no puede sentir aprecio por el Templo quien está en pecado. Así que Peralta debe confesar sus culpas (y el texto sigue con la confesión en primera persona): que es un miserable, un alocado y soberbio; que vendió por suyo el Festín sin ser su autor; que engañó al aprobador, el cual dio su visto bueno sin leerlo y ahora debería mandar que se recoja el escrito ${ }^{30}$. Su penitencia, en fin, será no escribir más en su vida y darse de azotes para desencantar a su pluma Dulcinea.

Tras el soneto que remata el Azote (y sobre el que volveré más abajo), viene un segundo romance, cuyo título arranca así: Vexamen a un Demonio o mal Poeta que ni a merecido lauro, ni quiere consentir que alguno lo meresca ${ }^{31}$. El intento

29. Peralta publicó, en efecto, una Festiva trompa al célebre aparatoso recevimiento del D. Ricardo Fanshau ... Embajador de Inglaterra (Sevilla, 1664); hay ejemplar en la Hispanic Society de Nueva York (José Simón Díaz, Bibliografía regional y local de España, Madrid, C.S.I.C, 1976, no 1495 (Cuadernos Bibliográficos, 33). Se trata de Sir Richard Fanshawe (1608-1666), diplomático con aficiones literarias; por ejemplo, tradujo al inglés poemas de Góngora y de los Argensola (algunos pueden leerse en Tony Frazer, ed., Spanish Poetry of the Golden Age in contemporary English translations, Exeter, Shearsman Books, 2008; véase Eduardo R. del Río, «The context of Translation: Richard Fanshawe and Spanish Verse», Revista Alicantina de Estudios Ingleses, 17, 2004, p. 65-80). Sir Richard llegó a Sevilla, procedente de Cádiz y Jerez, el 27 de marzo de 1664 y permaneció en la ciudad hasta el 3 de abril, alojándose en su Alcázar: "During our stay in this palace, we were every day entertained with a variety of recreations, as shows upon the river, stage plays, singing, dancing, men playing at legerdemain, which were constantly ushered in with very great banquets, and so finished" (The memoirs of Ann Lady Fanshawe, Londres - Nueva York, John Lane The Bodley Head, 1907, p. 137-140; cita, p. 139). Las citadas fechas marcan un término a quo para los escritos contra Peralta.

30. La aprobación está firmada por el jesuita Bernabé de Medina. El texto del Azote afirma en tono recriminatorio que no leyó lo que aprobó: «Dizen que a un docto vonete / engañé astuto [yo: Peralta]: concedo. / Pero no aprobara el padre / escrito que yo le llevo. / Claro está que él no lo vio / porque ver a un diablo inquieto / que vailaba la mariola / fuera cosa del infierno. / No sé cómo este varón / no procura recogerlo, / porque no digan: aprueba / lo malo como lo bueno. / Además que si leyera / que en conserva eché protervo / a la Virgen, me quemara / por nefando confitero" (Azote, f. 227v-228r). Los dos motivos aludidos, el de la mariola que el diablo quiso bailar con María y el de la conserva que la resguarda del pecado original, figuran en el texto del Festín. Pese a los aspavientos del Azote, este tipo de asociaciones no eran raras en la poesía religiosa de la época desde los tiempos de Alonso de Ledesma. Tiene interés, en fin, la nota marginal a la primera cuarteta: «Engañó a quien aprobó el Festín ocultándole la Sátyra». Con este término se refiere a los dos romances que ocupan el primer pliego del Festín. El segundo pliego empieza con un acróstico latino, acaso para dar la impresión de que ese iba a ser el preliminar de la obra. Véase, además, lo que se dice al respecto en la nota que sigue.

31. Ms. 58-2-25, f. 229r-234v. Y sigue, como si de una portada tipográfica se tratase: Recuperacion de lo ageno, que por grangeria manifesto la Invidia. Restitucion de lo improprio, que usurpô la mala inclinación al deseo de que los aciertos parescan errores, y la ignorancia pase plaza de discrecion. Por el mas insigne (hablando con perdon de Ioseph Roman), mayor reverenciador, e indigno defensor de la Torre mas conocida por sus prodigiosos efectos, nunca bastantemente alavada por sus muchos meritos, y más que medianamente acometida de Torresillas, q[ue] antes que empiecen à ser 
del poema es básicamente responder a las afirmaciones hechas por Peralta en el primero de los romances del Festín, para lo cual llega incluso a retomar algunos de sus términos, naturalmente que para devolvérselos con creces. Así las cosas, lo que tiene mayor relieve en el poema son las alusiones personales y algunas noticias literarias que nos da del tal Peralta. Por el Azote ya sabíamos que era dentón (y al tiempo desdentado). Ahora nos enteramos de que vestía medias con "los colores de lorito" (f. 232r); y el glosador apostilla que «trae siempre medias verdes, porque son las suyas únicas». Y que era autor de varias piezas poéticas de cuya venta se encargaban los ciegos.

Más rico todavía en este tipo de detalles es el romance que sigue, que bien podría ser obra del mismo muñidor del Sagrario ${ }^{32}$. Las noticias son ahora: que Peralta hizo una loa a una comedia, y la glosa apunta: «Hizo una sin que se la pidiesen, y leyéndola fue risa de los comediantes por mala.» Que no para de mandar coplas a la imprenta para que las vendan los ciegos. Que marchó a Madrid con idea de hacerse conocido en la corte; con esta glosa: «Dixo que iba a asombrar a Madrid, porque en Sev[ill]a no lo entendían.» Que a un hereje notorio llamó pio y beato en una obra suya, la ya citada entrada del embajador de Inglaterra en Sevilla, como aclara la glosa. Y antes de todo eso una curiosa caracterización de su estilo: «Tú que, alegórico y culto, / si algo con tu fiero idioma / pretendes sacar a luz / siempre se te queda en sombras» (f. 235r). Una afirmación hasta cierto punto inesperada y que tiene claros ecos de la querella antigongorina ${ }^{33}$.

La última respuesta que recibe el Festín es un texto en prosa que sí va firmado por Torre Farfán y que lleva por título Torre del Templo Panegírico ${ }^{34}$. El escrito

fabricadas las reduce a ruina su desvanecida locura. El Muñidor de la Cofradia del ssmo. Sacramento del Sagrario de la sta. Iglesia Ma[y]or dedicalo a quien no lo aprobo, aunque aprobo el festin de las tres Gracias, porque no estando en el, el Poeta fullero encaxo el Romance en el como carta de mas. El romance ocupa los f. 229r-234v del ms. 58-2-25. Inc.: «A ti escoria de las Musas, / poeta de pío pío». El final del largo rótulo deja clara la intención de exculpar al aprobador del Festín.

32. Romance contra la malicia de D[o]n Ioseph Roman de la Torre y Peralta, castigando el atrevimie[n] to de aver escrito contra D[o]n Fer[nan]do dela Torre. Ms. 58-2-25, f. 235r-236v. Inc.: «Torre Peralta o Román, / o vinagre o pasmarota».

33. Algo apuntaba ya en la misma dirección el propio Torre Farfán en el Templo. Así, en el vejamen que dedica a las octavas de Torre Peralta (f. 144r), leemos: «Faltando en lo dibuxado, / sobran [los versos] en lo colorido. / Grave enfermedad padece[n] / de conceptos, porque miro / que viniendo tan al olio, / nada al temple en ellos vino. / Muchos sí vienen al fresco, / en quien lo obscuro y lo frío / haze que pinte Noruegas, / o que componga Apeninos.» Lo que no obsta en absoluto para que Torre Farfán se declare rendido admirador de Góngora. Es sin duda una disociación digna de ser subrayada entre el gran cordobés y sus imitadores.

34. El título completo dice así: Torre del Templo Panegi[ri]co de D[o]n Fernando de la Torre Farfan. De donde se registra La calmnia [sic] de don Joseph de la Torre Peralta y se descubre su ignorancia. Manifiestase la detracción encerrada en el retiro de su celda, y se publica la murmuración escondida detrás de los tapiçes de vn camarin. El texto va inserto en una cartela dibujada, que lo contiene en una doble óvalo, uno por encima del otro, con adornos alusivos a la fama literaria (plumas, clarines) y rematada con una torre a modo de sagrario flanqueada por dos angelotes que sostienen una corona y un listel con la leyenda: Cunctas super ardua turris eminet, que proviene de Lucano, Farsalia, IV, 431-432. El escrito se extiende hasta el final del códice, ocupando 
va dividido en diez capítulos cada uno de ellos rotulado como Escudo y con un titulillo propio. Como pueden ayudar a hacerse una idea del desarrollo y contenido de la apología, los copio a continuación: Opónese la defensa a más eficazes armas que las que usa la detracción (10); Defiéndese la immunidad del Templo (2०); Demuestrase común y loable el uso de los retratos (3०), Descúbrese la viga en los ojos que vieron la paja en los agenos (40); Dase luz en común de el árbol de Apolo a los que se andan por las ramas (5०); Determinase el laurel infalible para adorno del retrato (6०); Dada la razón del tiempo de los laureles, pídese quenta de otros sin qué ni para qué (7o); Búscase la ceremonia antigua de los vexámenes $\left(8^{\circ}\right)$; Hállase la descendencia de este uso noble (9०); Despréciase la calumnia de llamar hurtos a las autoridades $\left(10^{\circ}\right)$. En cuanto a los argumentos defensivos y ofensivos que maneja Torre Farfán, bastará con resaltar, por ahora, que pone particular empeño en justificar el uso que hace en su libro de la corona de laurel (una costumbre que viene de antiguo) y del retrato (una práctica común, una especie de firma o reconocimiento de autoría que, en este caso, es responsabilidad de quien costeó la impresión). Por lo que hace a los vejámenes, su uso se justifica tanto por tener origen en la antigüedad como por encuadrarse dentro de las prácticas universitarias y académicas. Por lo demás, insiste Torre Farfán en presentar al cartujo como el verdadero instigador del libelo contra su libro y a Torre Peralta como alguien que había alquilado su pluma y hablaba por boca de ganso. La novedad con respecto a lo que sobre este punto ya decían los textos precedentes es que Farfán añade un tercer compinche, cuyo nombre no da pero que en diferentes pasajes identifica como un aprendiz de letrado (¿un abogado?), al que el título ya sitúa escondido detrás de los tapices de un camarín $^{35}$. Por último, se permite Farfán el lujo de recoger al final de su escrito una carta que le había mandado desde Sanlúcar de Barrameda, con fecha de 23 de diciembre de 1663, el médico Duarte Núnez de Acosta. En ella elogiaba el Templo panegírico tras acabar de leerlo y le remitía a Farfán un epigrama acróstico en latín que, de haberlo sabido con tiempo, habría podido servir -argumenta el médico- para los preliminares del libro ${ }^{36}$.

los f. 237r-292v. Presenta numerosas notas marginales que citan y referencian las autoridades aludidas en el texto.

35. Así lo dice en este pasaje: «QQué sería ver un sí es no es monge [i.e., Solís y Valenzuela] pared en medio de otro que no á acabado de començar a ser letrado, y ambos mezclados con otro [i.e., Torre Peralta] que no acertó a ser pintor y lo escupe (qué lindo tres en carro), hinchados de soplones de la erudición...» (f. 284r). Anteriormente había dicho, entiendo que refiriéndose a ese tercer hombre desconocido: «¿Quándo se asentarán en el bufete de los Bártulos y los Baldos los que desprecian el refectorio de los abades?» (f. 270r).

36. Está editado y traducido por Luis Charlo Brea, ed., Poesías latinas del Doctor Duarte Núñez de Acosta, Cádiz, Universidad de Cádiz, 1993, p. 242-245; en la introducción hay datos sobra la vida y actividad tanto profesional como literaria de este médico portugués. Se da la circunstancia curiosa de que es el poeta más representado (después de Farfán, claro), en el Templo, pues son nada menos que ocho las composiciones suyas, algunas de ellas remitidas a nombre de uno de sus hijos y de un yerno (todas figuran en el citado ms. 3891 de la BNE, el que transmite la Xícara). Todo el embrollo queda aclarado por una misiva del médico a Torre Farfán, de la que este se hace eco en $T P, 233 \mathrm{v}-234 \mathrm{r}$. Por otra parte, es posible que también sean suyos tres dísticos 
Una vez hecha la relación de los textos que salen en defensa de Farfán contra Peralta, intentaré reconstruir en sus líneas fundamentales el entramado conceptual que elaboran sus autores, lo que de paso dará ocasión para entrar en algunos pormenores que arrojan luz sobre el ambiente literario sevillano de la época. Doy por descontado que toda la apología se construye en torno a un eje que contrapone la virtud propia frente al vicio ajeno, pareja que se prolonga y se proyecta en otras como la de verdad $v$ s. mentira y la de saber $v$ s. ignorancia. Lo interesante es ver en qué términos se concreta esa oposición básica, según los esquemas y procedimientos habituales en los escritos de polémica literaria que, como es sabido, se mueven entre lo judicial y lo demostrativo o epidíctico.

Hay un primer eje conceptual que determina una jerarquía, en principio social pero que luego se hace también literaria, con dos niveles de realización, uno mundano (hidalguía $v$ s. villanía) y otro que lo subsume y lo trasciende: sacralidad vs. profanidad (incluso herejía). La doble condición, hidalga y sacerdotal, de Farfán, subrayada desde el mismo texto introductorio de la polémica por Diego I. de Góngora, le confiere una superioridad indiscutible sobre Peralta, a quien se le echa en cara su villanía en repetidas ocasiones y en diferentes registros (social, personal, literario). Valga como muestra esta cuarteta del Azote: «La infame acción no rubrica / el noble, solo el plebeyo / sin honrra en sátyra vil / pusiera su nombre impreso ${ }^{37}$.» Este pasaje viene a abonar, a mi juicio, la autoría del anónimo Azote por parte de Farfán, ya que no sería acción noble por su parte firmar una sátira. El argumento se desarrolla luego:

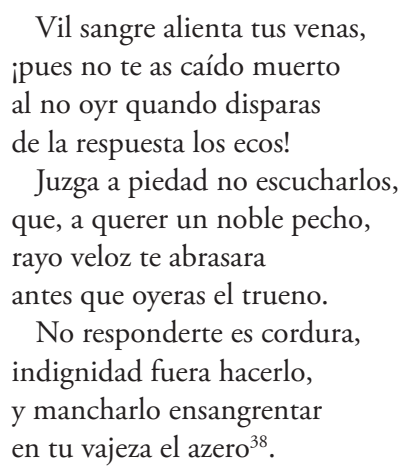

La inevitable transición hacia el plano religioso viene propiciada por el carácter del libro que está en el origen de la polémica, cuyo título, Templo panegírico, indica que ya es en sí mismo un templo levantado en honor de

epigramáticos que a nombre de Duarte Núñez de León aparecen recogidos al final del Escudo noveno de la Torre (f. 283r-v); por la posición que ocupan en el texto, cabe pensar que se trata de un añadido con que se agradece la recepción de la carta antedicha.

37. Azote, f. 223v. Los ataques contra el rival no ahorran, por lo demás, otras derivaciones. Así, la vileza lleva aparejada la pobreza, el hambre: en el caso de Peralta, «imperó el hambre mísera sobre el temor valiente. Valiose del adagio, no por noticia sino por instinto: El asno hambriento no teme el palo» (Torre, f. 242v).

38. Azote, f. $225 \mathrm{r}-\mathrm{v}$. 
María y del Santísimo Sacramento ${ }^{39}$. De manera que atacar el Templo equivale a profanarlo. La casualidad, además, de que dos de los contrincantes se apelliden Torre da pie, por su lado, a contraposiciones más o menos ingeniosas en los dos niveles antes señalados. Merece la pena recordar al respecto el soneto que remata el Azote:

\section{Del proprio autor del romance a Don Joseph del [sic] Torre, por la mesma causa}

Mísera torre que con vajo intento del polvo humilde levantarte quieres, abate la soberbia, nunca esperes ascender a mayor sin fundamento.

De otra, ya consagrada, el sabio aliento (con que sube a dezir al sol quién eres) adora atenta, que tu estrago adquieres si conspira a su ardor tu atrevimiento.

Mas ya de tu ruina persuadida en vano te procuro, pues osada llegaste a su región, desvanecida.

Que el cielo, de quien esta es amparada, tiene, al paso que subes presumida, eficaces los golpes de la espada ${ }^{40}$.

Se contraponen aquí dos torres, una miserable que con osada soberbia quiere alzarse a mayor, frente a otra eminente y consagrada que goza de la protección celestial. La analogía iconológica que establecía el primer grabado del Templo entre la Giralda (la Torre mayor de Sevilla) y el propio libro, se traslada, como cabía sospechar al propio autor: Farfán es la mayor torre de la poesía sevillana. La idea se hace transparente en diferentes pasajes de la polémica. Por ejemplo, en el Azote, dirigiéndose a Peralta: «¿No tiemblas de ver su torre / fortísima [del Templo], a quien el cielo / para su amparo le dio / tan seguros fundamentos ${ }^{41}$ ?» Farfán, sacerdote que, según los datos que tenemos, estaba en muy buenos términos con el cabildo catedralicio, se mueve a sus anchas en este terreno, por lo que pasar a las denuncias y de ahí a las amenazas le resulta muy fácil. Así que, como cabía esperar, Peralta no se libra de las acusaciones de pecador y de connivente con la herejía. Particularmente, esta última sale a relucir en varias ocasiones con motivo de la ya mencionada relación que hizo de la visita a Sevilla del embajador de Inglaterra: «Ya le vimos de molde piando por coger

39. Al tiempo que remite a una tradición de poesía encomiástica que incluye, entre otras muchas, una obra como Il tempio panegirico del cavalier Marino alla maestà christianissima di Maria de' Medici... (Lyon, 1615).

40. Azote, f. $228 \mathrm{v}$.

41. Azote, f. 222r. Recuérdese que el remate renacentista de la Giralda ostenta la leyenda TVRRIS FORTISSIMA NOMEN DNI PROVERB. 18, que es obviamente cita de Proverbios, 18, 10. La idea reaparece luego en la Torre, f. 242v: «Exageraba un serolo [sic] que avía semejante a la de Sevilla una torre en Marruecos. Replicó otro considerado que les atendiese a las situaciones: una apoiando las infidelidades de África, y otra coronando la religión de Andalucía...». 
las migajas de la impía messa $[s i c]$ de Calvino $»^{42}$. Peralta debía saber, por tanto, que pendía sobre su cabeza la espada del castigo, como apunta el último verso del soneto, o que podía acabar en el fuego de la hoguera: «Aquí para entre nosotros, / mejor es no hazer ruido, / no sea que el chamuscón / te venga del Santo Oficio», le espeta el muñidor del Sagrario ${ }^{43}$.

De este primer eje (hidalguía vs. villanía) deriva todavía otra pareja conceptual que lo desarrolla en un aspecto específico y que ya asoma en algunos de los pasajes que se han citado: gratuidad vs. venalidad. Mientras que los escritos de Farfán son presentados como desinteresadas emanaciones de la cultura y la devoción de su autor, cuya impresión costean otros, los de sus oponentes son valorados como baratijas que sus autores ponen a la venta por mero afán de lucro o de notoriedad. En este sentido, la polémica abunda en alusiones a la imprenta, a los productos tipográficos y a los personajes que participan en el proceso de su producción, autorización y comercialización.

Como ya se ha dicho, a ojos de Farfán y de sus amigos, la de Peralta es una pluma de alquiler que se ha puesto al servicio de Valenzuela, aunque en vano, ya que finalmente, después de dar la cara por el otro, se ha quedado sin $\operatorname{cobrar}^{44}$. Pero este no ha sido sino un paso más en su trayectoria de versificador por dinero: "Vendiole al embaxa[d]or herege los versos como lo á de uso y costumbre», dice una de las apostillas del códice ${ }^{45}$. Pero los versos son tales que solo los ciegos (porque no pueden leerlos) se atreven a venderlos (Azote, f. 222v). En este punto de la relación de Peralta con los ciegos insiste mucho el muñidor del Sagrario, que llega incluso a darnos lo que parece el apodo de uno de ellos:

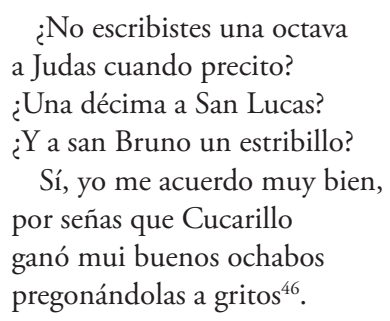

42. Torre, f. 242r. Dice la glosa: «Escribió con muchas impiedades la entrada del Embaja[d] or de Ingalaterra, más atento a la codisia que a la Religion». Otras referencias a ese mismo impreso: Azote, f. 226v-227r; Romance contra la malicia, f. 236r. Del mismo tenor es esta otra acusación contra el Festín: «un libelo (...) entre apostaçias (...), un prólogo en todo luterano» (Torre, f. 248r).

43. Romance, f. 233r. Compárese con la confesión que supuestamente hace Peralta al final del Azote, f. 228, dirigiéndose al censor del Festín: «Además que si leyera / que en conserva eché protervo / a la Virgen, que me quemara / por nefando confitero». Peralta había sido el primero en mencionar los ritos inquisitoriales: "Quando no por los errores / que fraguó su desatino, / por el salir en estatua [Torre Farfán, en alusión al grabado del Templo], / solo él del fuego era digno» (Festin, A3v).

44. Por ejemplo: «...el interés de poca paga, que no logró [Peralta], le quitó todo el miedo de cómplice» (Torre, f. [244bis]).

45. Azote, f. $227 \mathrm{r}$

46. Romance, f. 232v-233r. Otras alusiones en f. 233v y f. 235v, con esta glosa: «Solo p[orqu] 
Pero, según sus rivales, Peralta no se detiene ante nada y sus trapacerías llegan al extremo de engañar a los censores, como ya se ha dicho. De manera que mandó a aprobar el texto del Festín ocultando las sátiras que luego se imprimieron en el primer pliego: una razón, entre otras más, para que el libelo fuese retirado de la circulación ${ }^{47}$. Su uso de la imprenta es, en definitiva, espurio y equivocado, ya que esta tiene como función básica la de dar o quitar la fama al escritor: «QQué fácilmente a la prensa / das [Peralta] tu nombre sin consejo! / Mira que es la prensa misma / quien lo destruie más presto» (Azote, f. 223r). Por eso, en el pleito que se ha levantado entre ellos, Farfán tiene a su favor 1.500 testigos, que son los ejemplares que se han tirado de su libro (Torre, $\mathrm{f}$. $244 \mathrm{v})$.

En el caso de Valenzuela, aunque con matices, las cosas no son muy distintas. Si Peralta es poco más que un buhonero de versos, el cartujo aspira a mercader. Los textos van estableciendo una analogía entre la conexión ultramarina que mantienen los dos hermanos novogranatenses con los negocios de los comerciantes entre España y las Indias. El papel de financiero recae sobre Pedro, mientras que Bruno es quien malgasta sus remesas imprimiendo en la metrópoli escritos suyos o de su hermano. Así presenta Farfán el tejemaneje de haber publicado en Sevilla una obra, probablemente de Bruno, con el retrato de Pedro, laureado y en pose de limosnero:

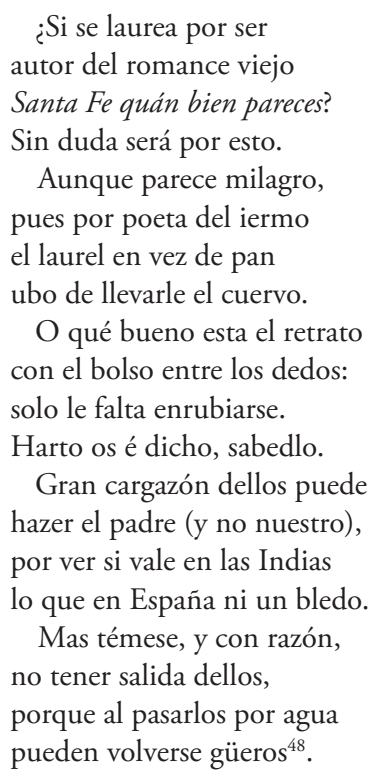

e los ciegos las vendan, son sus coplas como las de D[o]n Gaiferos». De todos los poemas que ahí se mencionan solo tengo noticia de uno: Canción real al retiro y penitencia del patriarca san Bruno en el desierto, Sevilla, s.n. Hay ejemplar en la Hispanic Society de Nueva York.

47. Remito otra vez a Azote, f. $227 \mathrm{v}-228 \mathrm{r}$, así como al remate de la portadilla que precede al Vexamen a un Demonio (véase más arriba la n. 31). Véase además, Torre, f. 247v-248r.

48. Azote, f. $225 \mathrm{r}-\mathrm{v}$. El mentado retrato da pie a nuevas alusiones a las negocios editoriales de los dos hermanos en la Torre, f. 268r-271r. 
Pasaje en el que se emplean en tono peyorativo términos propios del comercio indiano y se proyecta una imagen desdeñosa de dicha actividad. Un similar tono desdeńoso hacia lo americano se trasluce en otros lugares, como este: «La América se inficiona con la malicia de un áspid que, aunque mudo [es Bruno], lo descubre un cascabel que tiene en la cabeça. Raras propiedades malquistan la naturaleza de algunos avechuchos criollos ${ }^{49}$."

Todo esto señala con claridad otro de los ejes conceptuales que articulan la polémica y que se constituye en torno a la pareja centralidad $v s$. marginalidad. Porque a los orígenes neogranadinos de los hermanos Valenzuela, se suma también la condición de forastero de Peralta, quien se presenta a sí mismo en estos términos: «Por desfazer cierto tuerto / que en cierta justa se hizo, / aventurero de allende, / la pluma en la mano enristro" ${ }^{50}$. Versos en los que, con sus claras resonancias de los desafíos propios de las narraciones caballerescas, seguramente hay que interpretar de allende como 'ultramarino', indicando así un origen extrapeninsular (canario o americano) de Peralta ${ }^{51}$. Frente a la extranjería de sus rivales, Farfán esgrime con orgullo la pertenencia a «nuestra tantas vezes noble Sevilla» (Torre, f. 274r) y su incardinación andaluza o bética, como él gusta de decir. Raigambre que naturalmente va más allá de lo geográfico, ya que establece la pertenencia a una tradición literaria y cultural.

Bien se deja ver en el escudo sexto de la Torre, consagrado a justificar la utilización del laurel en el retrato mediante citas de diferentes autores antiguos y modernos. Pues bien, entre los modernos los hay italianos (Torquato Tasso, Marino, Guarini) y los hay españoles, hasta un total de ocho citas repartidas entre Herrera, Góngora y Lope. A Herrera se remite cinco veces, siempre en su faceta poética y teniendo a la vista la edición póstuma de sus Versos (1619); lo suele llamar «nuestro» y también por dos veces «divino». Pero más allá de la vinculación que Farfán quiere establecer aquí entre él mismo y Herrera como paisano y como modelo de poeta erudito, la serie de autoridades que jalonan el capítulo es ilustrativa de su voluntad de pertenencia a una tradición culta que va de los ilustres modernos hasta los clásicos de la antigüedad, raigambre con la que quiere afirmar su posición de preeminencia en el Parnaso sevillano del momento. Todo ello en marcado contraste con la caracterización de sus rivales como bufones cuyas obras no pasan de ser fruslerías, cuando no caen de lleno en la vulgaridad ${ }^{52}$.

49. Torre, f. 244 r. Otros motes del mismo tenor: «efigie ultramarina», «Tobías de allende el mar», refiriéndose al retrato de Pedro (Torre, f. 268v).

50. Festín, A3r. El muñidor del Sagrario, por su parte, le replica: «Aventurero de allende / te confiesas en tu escrito, / y es escusado, pues consta / de lo poco conocido" (Romance, f. 230v).

51. Cf., por ejemplo: «Pero, sobre todos, estaba bien [don Quijote] con Reinaldos de Montalbán, y más cuando le veía salir de su castillo y robar cuantos topaba, y cuando en allende robó aquel ídolo de Mahoma que era todo de oro, según dice su historia» (Quijote, ed. F. Rico, Barcelona, Crítica, 1998, v. I, p. 40).

52. Las citas al respecto podrían multiplicarse. El muñidor del Sagrario, por ejemplo, empieza así su primer romance contra Peralta: «A ti, escoria de las Musas, / poeta de pío pío, / conceptillo chabacano / que hurtaste de Estevanillo» (f. 230r). En cuanto a Valenzuela, los escudos cuarto, séptimo y décimo de la Torre están plagados de burlas sobre sus jeroglíficos desplegables (que 
Ese afán de centralidad explica que Farfán remate su Torre con una defensa del uso de autoridades en los escritos, defensa que a mi entender no viene al caso, pues lo único que se le reprochaba en el Festín es que para componer sus vejámenes hubiese tenido que recurrir a citar y traducir los versos de Marcial y John Owen, entre otros. Resulta, pues, evidente que en este punto quiso tomar el rábano por la hojas y aprovechar la ocasión de revestirse de la dignidad del viejo Humanismo en lo tocante a la defensa de la erudición y su empleo.

Erudición y lecturas no le faltaban, desde luego, a Torre Farfán -otra cosa es como las había digerido-. Es obvio que buena parte de las autoridades que cita provienen de polianteas ${ }^{53}$, pero también demuestra tener un conocimiento directo de buen número de autores, tanto antiguos como modernos. Que la mayor parte de sus referencias estén tomadas de obras en latín nos priva de saber con precisión hasta qué punto tenía familiaridad con los autores contemporáneos en lengua vernácula, especialmente los poetas. Pero algunos apuntes nos ha dejado al respecto, como las ya mencionadas citas de ingenios españoles e italianos que agavilla en el escudo sexto de la Torre, o los nombres que saca a relucir en las cédulas jocosas de la justa ${ }^{54}$. A esto cabe añadir todavía un eco de los preliminares de González de Salas al Parnaso de Quevedo ${ }^{55}$ y, ya en el Azote, un par de alusiones cómicas basadas en el Quijote $e^{56}$. En conjunto, la conclusión que cabe extraer de estos materiales es que Farfán quiere insertarse como un eslabón más en la cadena de la poesía española y, en particular sevillana, desde los tiempos de Fernando de Herrera en adelante, aun a costa de pasar por alto la distancia estética y cultural que lo separa de aquellos referentes.

Lo que de verdad ocupaba a Farfán era el dar con la estrategia adecuada a la hora de diseñar su carrera literaria. De hecho, la polémica aquí estudiada

a Farfán le parecen habilidades propias de dueñas: Torre, f. 250r) y sus versos de poca monta.

53. Por ejemplo, cuando en el primer escudo de la Torre, haciendo un discurso sobre la envidia y la ignorancia, cita, entre otros, a Cicerón, Tito Livio, Séneca el Joven, San Agustín, Santo Tomás o Pierio Valeriano.

54. Farfán menciona, pero sin dar citas textuales, a Góngora (Soledades), Pérez de Montalbán (Para todos) y Cayrasco de Figueroa (Templo militante). Y al final amenaza de este modo a un poeta ladrón: «la maldición de Lope, Gongora, Villayzán, Calderón venga sobre sus coplas» (f. 59v).

55. La mención del grande Quevedo (f. 48v) surge cuando Farfán afirma que su editor juzga anónimo el epigrama Nomina Musarum o De Musis atribuido a Ausonio. La alusión (que no es del todo exacta) se refiere a un pasaje de González de Salas en los preliminares de la musa Melpómene acerca de la controvertida autoría del citado epigrama; véase Miguel Á. Candelas, «La erudición ingeniosa de González de Salas en los preliminares de la poesía de Quevedo», La Perinola, 7 (2003), p. 147-189, esp. 154-155.

56. Así, burlándose del desplegable de Valenzuela: «Porque doblar un papel / de baratijas, avierto [sic] / haze el quadro que Quixote / desvarató de Gaiferos» (f. 221v); o la supuesta confesión de Peralta al final de la pieza: «Prometo darme de azotes / o que me den, por si puedo / a mi pluma Dulcinea / sacarla de encantamento» (f. 228). También el muñidor del Sagrario moteja a Peralta como «Don Quixote de poquito» (f. 230r). «Historiador de poquito» había llamado antes Peralta a Farfán (Festín, A3v). 
tiene como trasfondo la competencia (desigual, todo hay que decirlo) entre dos autores que quieren ocupar un lugar preeminente en el Parnaso sevillano de su tiempo. Un lugar que, en función del contexto social y literario, les lleva a poner la pluma al servicio de las instituciones que gobiernan la vida local. Estas son las que, con sus encargos, determinan y sancionan la valía de un escritor. Por eso, Farfán se enorgullece de su condición de poeta público; pero, eso sí: con un discurso en el que defiende que el único capital que cuenta es el simbólico. 